\title{
Assessment of DemDx, a differential diagnosis tool, and its accuracy at diagnosing patients in an ED setting
}

\author{
Authors: Cian Murphy ${ }^{\mathrm{A}}$ and Lorin Gresser ${ }^{\mathrm{B}}$
}

\begin{abstract}
Aims
Validation of a computer programme that can accurately diagnose patients would yield multiple benefits. Increased diagnostic accuracy would reduce referrals to secondary care, reducing medical mismanagement issues while offering patients more appropriate care in a shorter timeframe. Additionally, this would likely increase patient satisfaction, another vital metric of clinical outcomes. The aim of this project was to assess the accuracy of the iPhone and Web app DemDx at diagnosing patients in an emergency department (ED) setting.
\end{abstract}

\section{Methods}

Anonymised clinical records for 100 patients were retrospectively obtained from the ED in Beth Israel Deaconess Medical Center, Boston, USA. This contained the differential diagnoses from the clerking junior doctor, who performed the initial assessment (D1) (Table 1). In addition, the discharge diagnosis was included which was used as the gold standard diagnosis for this study (D2). Two research assistants used these data to generate a diagnosis from DemDx. These app diagnoses were both compared with the clerking differentials and the discharge diagnosis.

\section{Results}

The D1 differentials agreed with D2 in $74.44 \%$ of cases while DemDx agreed with D2 in $85.56 \%$ of cases. In this comparison, DemDx outperformed the junior doctors $(p=0.02)$. When the first, and thus most likely, differential was taken from D1 and DemDx, they agreed with D2 in 20 and $18.8 \%$ of cases, respectively $(p=0.7365)$.

\section{Conclusion}

This study has shown that DemDx can diagnose patients as well as junior doctors in their second year after medical school. The doctors in this study scored at least in the 70th percentile in the United States Medical Licensing Exam (USMLE). This thus shows that DemDx represents a democratisation of access to such clinical acumen. This may improve clinical outcomes, especially in more resource-limited settings.

Authors: ${ }^{\mathrm{A}}$ University of Warwick and DemDx; ${ }^{\mathrm{B}}$ DemDx

\begin{tabular}{|c|c|c|c|}
\hline $\begin{array}{l}\text { Presenting } \\
\text { complaint }\end{array}$ & $\begin{array}{l}\text { Clerking } \\
\text { differential } \\
\text { (D1) }\end{array}$ & $\begin{array}{l}\text { DemDx } \\
\text { differential }\end{array}$ & $\begin{array}{l}\text { Discharge } \\
\text { diagnosis (D2) }\end{array}$ \\
\hline $\begin{array}{l}\text { Jaundice, } \\
\text { watery stools }\end{array}$ & $\begin{array}{l}\text { Cholecysitis, } \\
\text { kidney } \\
\text { stones }\end{array}$ & $\begin{array}{l}\text { Ascending } \\
\text { acute } \\
\text { cholangitis }\end{array}$ & $\begin{array}{l}\text { Cholangitis, } \\
\text { choledocholithiasis }\end{array}$ \\
\hline $\begin{array}{l}\text { Acute on } \\
\text { chronic } \\
\text { headaches, } \\
\text { photophobia, } \\
\text { constant, } \\
\text { worse when } \\
\text { lying flat, } \\
\text { tender over } \\
\text { jaw, radiate } \\
\text { back towards } \\
\text { left neck. No } \\
\text { thunderclap }\end{array}$ & Migraine & Migraine & Migraine \\
\hline
\end{tabular}

\section{Conflict of interest statement}

DemDx applications and downloads are produced by Dem DX Limited - a registered company in London, England (registered company number: 09573122). The lead researcher works part-time as a technical consultant for DemDx. This naturally raises questions about conflicts of interest. To minimise this, the study tasks were separated. As mentioned in the methods, the entirety of the app's usage was performed by two research assistants. They are unaffiliated with DemDx, and did this work for free because they work in Beth Israel Hospital, the location for this study. 